\title{
IPA Summary of Analysis
}

Analysis Name: new database total - 2010-12-27 10:24 PM

Analysis Creation Date: 2010-12-27

IPA version: 8.8 (Release Date: 2010-11-13)

Content version: 3204 (Release Date: 2010-10-27)

\section{Analysis settings}

View

Reference set: Ingenuity Knowledge Base (Genes + Endogenous Chemicals)

Relationship to include: Direct and Indirect

Includes Endogenous Chemicals

Optional Analyses: My Pathways My List

Filter Summary:

Consider only molecules and/or relationships where

species $=$ Human

\section{Top Networks}

ID Associated Network Functions Score

Cancer, Renal and Urological Disease, Cell Cycle

Connective Tissue Development and Function, Cancer, Gastrointestinal Disease

26

Cell Cycle, Endocrine System Development and Function, Small Molecule Biochemistry

21

Genetic Disorder, Skeletal and Muscular Disorders, Inflammatory Disease

2

(c) 2000-2010 Ingenuity Systems, Inc. All rights reserved. 


\section{Top Bio Functions}

\section{Diseases and Disorders}

Name

$2.21 E-04-4.93 E-02$

Cancer

Renal and Urological Disease

$2.21 \mathrm{E}-04-2.98 \mathrm{E}-02 \quad 3$

Gastrointestinal Disease

4.61E-04 - 3.07E-02 10

Genetic Disorder

9.47E-04-4.13E-02 26

Connective Tissue Disorders

$1.38 \mathrm{E}-03-7.54 \mathrm{E}-03 \quad 2$

\section{Molecular and Cellular Functions}

Name

Cell Cycle

p-value

DNA Replication, Recombination, and Repair

1.90E-05 - 4.93E-02 12

Energy Production

8.34E-05 - 4.44E-02

8.34E-05 - 8.34E-05

Nucleic Acid Metabolism

$8.34 \mathrm{E}-05-8.34 \mathrm{E}-05$

Small Molecule Biochemistry

$8.34 \mathrm{E}-05-1.75 \mathrm{E}-02$

\# Molecules

12

12

3

3

4

\section{Physiological System Development and Function}

Name

Hematological System Development and Function

Hematopoiesis

Connective Tissue Development and Function

Embryonic Development

Nervous System Development and Function

p-value

9.47E-04 - 3.47E-02

9.47E-04 - 3.47E-02

2.38E-03 - 4.93E-02

2.52E-03 - 2.00E-02

2.52E-03 - 4.93E-02
\# Molecules

4

3

8

4

2 


\section{Top Canonical Pathways}

Name

p-value

Ratio

Mismatch Repair in Eukaryotes

7.25E-04

$2 / 20(0.1)$

Role of CHK Proteins in Cell Cycle Checkpoint Control

$3.11 \mathrm{E}-03$

$2 / 35(0.057)$

Role of BRCA1 in DNA Damage Response

8.73E-03

$2 / 58(0.034)$

Valine, Leucine and Isoleucine Biosynthesis

2.98E-02

$1 / 12(0.083)$

Hereditary Breast Cancer Signaling

3.44E-02

2/122 (0.016)

\section{Top Molecules}

\section{Fold Change up-regulated}

Molecules

Exp. Value

ECT2

$\uparrow 1.870$

TPX2

$\uparrow 1.680$

PMEPA1

$\uparrow 1.610$

UBE2C

$+1.570$

CENPF

$\uparrow 1.500$

FAM91A1

$\uparrow 1.380$

ATAD2

$\uparrow 1.370$

$\mathrm{NOTCH} 1$

$\uparrow 1.270$

ATP1B3

$\uparrow 1.240$

AURKA

$\uparrow 1.240$

\section{Fold Change down-regulated}

Molecules

Exp. Value

S100P

$\downarrow-1.800$

PLAC8

$\downarrow-1.710$

Exp. Chart

(c) 2000-2010 Ingenuity Systems, Inc. All rights reserved. 
CBR1

$\downarrow-1.170$

CYB5A 
Top My Lists

Name

p-value

Ratio

Top My Pathways

Name

p-value

Ratio

\section{Top Tox Lists}

Name

p-value

8.23E-02

Ratio

Cell Cycle: G2/M DNA Damage Checkpoint Regulation

1.62E-01

$1 / 34(0.029)$

Hypoxia-Inducible Factor Signaling

NRF2-mediated Oxidative Stress Response

3.8E-01

1/70 (0.014)

$1 / 188(0.005)$ 


\section{Top Tox Functions}

\section{Assays: Clinical Chemistry and Hematology}

Name

Increased Levels of Alkaline Phosphatase

\section{Cardiotoxicity}

Name

Cardiac Damage

Congenital Heart Anomaly

Cardiac Arteriopathy

Hepatotoxicity

Name

Liver Cirrhosis

Hepatocellular Carcinoma

p-value

4.96E-02 - 1.75E-01

1.01E-01 - 1.01E-01

2

3.23E-02 - 3.23E-02 1

5.40E-02 - 5.40E-02 1

$1.00 \mathrm{E} 00-1.00 \mathrm{E} 00 \quad 2$

\section{Nephrotoxicity}

Name

Renal Transformation

p-value

1.00E-02 - 1.00E-02

\# Molecules

1 